\title{
Fixed point and common fixed point results in ordered cone metric spaces
}

\author{
Binayak S. Choudhury, N. Metiya
}

\begin{abstract}
In this paper we establish some fixed point results for functions which satisfy certain weak contractive inequalities in partially ordered cone metric spaces. We have also given some illustrative examples. Our results are extension of some existing results.
\end{abstract}

\section{Introduction}

Cone metric space is a recently introduced generalization of metric space where every pair of elements is assigned to an element of a Banach space equipped with a cone which induces a natural partial order [16]. Fixed point studies were initiated in such spaces in the same work. Other fixed point theorems in cone metric spaces were deduced in several other recently published works, some of which are noted in $[10,14,17,19,20,24]$.

In recent times, fixed point theory has developed rapidly in partially ordered metric spaces; that is, metric spaces endowed with a partial ordering. An early result in this direction was established by Turinici in ordered metrizable uniform spaces [28]. Later Ran and Reurings established a fixed point result in partially ordered metric spaces and applied it to solve certain matrix equations [25]. The fixed point result of Ran and Reurings [25] can be obtained by an application of the result due to Turinici [28]. Several other more recent works in this area are noted in $[1,15,18,23]$. Fixed point problems have also been considered in partially ordered cone metric spaces [3].

Weak contraction principle is a generalization of Banach's contraction principle which was first given by Alber et al. in Hilbert spaces [2] and subsequently

Key Words: Partially ordered set; Cone metric space; Weak contractive inequality; Control function; Fixed point.

2010 Mathematics Subject Classification: 54H10, 54H25

Received: November, 2011.

Accepted: February, 2012. 
extended to metric spaces by Rhoades [26]. Fixed point problems involving weak contractions and mappings satisfying weak contraction type inequalities have been considered in several works like [4, 12, 13, 29]. Particularly, in cone metric spaces the weak contraction principle was extended by the present authors [9].

The use of control function in fixed point theory was initiated by Khan et al. [21] which they called Altering distance function. This function has been used in obtaining fixed point results in metric spaces $[5,22,27]$ and probabilistic metric spaces $[7,8]$. It has also been used in multivalued and fuzzy fixed point problems [6].

In this paper we have proved some fixed point results in cone metric spaces having a partial order by using a control function. Precisely, we show that certain functions will have fixed points if they satisfy certain weak contractive inequalities. In [3], Altun et al. had obtained Ciric type fixed point results in partially ordered cone metric spaces. Our results extend the results of [3] in the special ordered cone metric spaces where the cone metric $d(x, y)$ for $x \neq y$, is constrained to the interior of the cone. We have given some examples to illustrate our results.

\section{Mathematical Preliminaries}

Definition 2.1([16]) Let $E$ always be a real Banach space and $P$ a subset of $E$. $P$ is called a cone if and only if:

(i) $P$ is nonempty, closed, and $P \neq\{0\}$,

(ii) $a, b \in \mathbb{R}, a, b \geq 0, x, y \in P \Longrightarrow a x+b y \in P$,

(iii) $x \in P$ and $-x \in P \Longrightarrow x=0$.

Given a cone $P \subset E$, a partial ordering $\leq$ with respect to $P$ is naturally defined by $x \leq y$ if and only if $y-x \in P$, for $x, y \in E$. We shall write $x<y$ to indicate that $x \leq y$ but $x \neq y$, while $x \ll y$ will stand for $y-x \in \operatorname{int} P$, where $\operatorname{int} P$ denotes the interior of $P$.

The cone $P$ is said to be normal if there exists a real number $K>0$ such that for all $x, y \in E$,

$0 \leq x \leq y \Rightarrow\|x\| \leq K\|y\|$.

The least positive number $K$ satisfying the above statement is called the normal constant of $P$.

The cone $\mathrm{P}$ is called regular if every increasing sequence which is bounded from above is convergent; that is, if $\left\{x_{n}\right\}$ is a sequence such that

$x_{1} \leq x_{2} \leq \ldots \leq x_{n} \leq \ldots \leq y$

for some $y \in E$, then there is $x \in E$ such that $\left\|x_{n}-x\right\| \longrightarrow 0$ as $n \longrightarrow \infty$. Equivalently, the cone $\mathrm{P}$ is regular if and only if every decreasing sequence which is bounded from below is convergent. It is well known that a regular 
cone is a normal cone.

In the following we always suppose that $\mathrm{E}$ is a real Banach space with cone $\mathrm{P}$ in $\mathrm{E}$ with $\operatorname{int} P \neq \emptyset$ and $\leq$ is the partial ordering with respect to $\mathrm{P}$.

Definition 2.2 Let $\psi: P \longrightarrow P$ be a function.

(i) We say $\psi$ is strongly monotone increasing if for $x, y \in P, x \leq y \Longleftrightarrow$ $\psi(x) \leq \psi(y)$.

(ii) $\psi$ is said to be continuous at $x_{0} \in P$ if for any sequence $\left\{x_{n}\right\}$ in $P$, $x_{n} \longrightarrow x_{0} \Longrightarrow \psi\left(x_{n}\right) \longrightarrow \psi\left(x_{0}\right)$.

The following is the definition of Altering distance function in cone metric space.

Definition 2.3 A function $\psi: P \longrightarrow P$ is called an Altering distance function if the following properties are satisfied:

(i) $\psi$ is strongly monotone increasing and continuous,

(ii) $\psi(t)=0$ if and only if $t=0$.

Definition $2.4([16])$ Let $X$ be a nonempty set. Let the mapping $d: X \times$ $X \longrightarrow E$ satisfies

(i) $0 \leq d(x, y)$, for all $x, y \in X$ and $d(x, y)=0$ if and only if $x=y$,

(ii) $d(x, y)=d(y, x)$, for all $x, y \in X$,

(iii) $d(x, y) \leq d(x, z)+d(z, y)$, for all $x, y, z \in X$.

Then $d$ is called a cone metric on $X$ and $(X, d)$ is called a cone metric space. Definition 2.5 ([16]) Let $(X, d)$ be a cone metric space and $\left\{x_{n}\right\}$ a sequence in $X$.

(i) $\left\{x_{n}\right\}$ converges to $x \in X$ if for every $c \in E$ with $0 \ll c$ there exists $n_{0} \in \mathbf{N}$ such that for all $n>n_{0}, d\left(x_{n}, x\right) \ll c$. We denote this by $\lim _{n} x_{n}=x$ or $x_{n} \longrightarrow x$ as $n \longrightarrow \infty$.

(ii) If for every $c \in E$ with $0 \ll c$ there exists $n_{0} \in \mathbf{N}$ such that for all $n, m>n_{0}, d\left(x_{n}, x_{m}\right) \ll c$, then $\left\{x_{n}\right\}$ is called a Cauchy sequence.

A cone metric space $X$ is said to be complete if every Cauchy sequence in $X$ is convergent in $X[16]$.

Definition 2.6 ([17]) Let $(X, d)$ be a cone metric space, $f: X \longrightarrow X$ and $x_{0} \in X$. Then the function $f$ is continuous at $x_{0}$ if for any sequence $\left\{x_{n}\right\}$ in $X, x_{n} \longrightarrow x_{0}$ implies $f x_{n} \longrightarrow f x_{0}$.

Definition 2.7 ([3]) Let $(X, \preceq)$ be a partially ordered set. Two mappings 
$f, g: X \longrightarrow X$ are said to be weakly increasing if $f x \preceq g f x$ and $g x \preceq f g x$ hold for all $x \in X$.

Definition 2.8 ([15]) Let $(X, \preceq)$ be a partially ordered set and $T: X \longrightarrow X$ be a self map. We say that $T$ is monotone nondecreasing if $x, y \in X, x \preceq$ $y \Longrightarrow T x \preceq T y$.

Lemma 2.1 ([16]) Let $(X, d)$ be a cone metric space, $P$ be a normal cone and $\left\{x_{n}\right\}$ be a sequence in $X$. Then:

(i) $\left\{x_{n}\right\}$ converges to $x$ if and only if $d\left(x_{n}, x\right) \longrightarrow 0$ as $n \longrightarrow \infty$,

(ii) $\left\{x_{n}\right\}$ is a Cauchy sequence if and only if $d\left(x_{n}, x_{m}\right) \longrightarrow 0$ as $n, m \longrightarrow \infty$.

Lemma 2.2 Let $\mathrm{E}$ be a real Banach space with cone $\mathrm{P}$ in $\mathrm{E}$. Then

(i) if $a \leq b$ and $b \ll c$, then $a \ll c[19]$,

(ii) if $a \ll b$ and $b \ll c$, then $a \ll c[19]$,

(iii) if $0 \leq x \leq y$ and $a \geq 0$, where $a$ is real number, then $0 \leq a x \leq a y$ [19],

(iv) if $0 \leq x_{n} \leq y_{n}$, for $n \in \mathbf{N}$ and $\lim _{n} x_{n}=x, \lim _{n} y_{n}=y$, then $0 \leq x \leq y$ [19],

(v) $P$ is normal if and only if $x_{n} \leq y_{n} \leq z_{n}$ and $\lim _{n} x_{n}=\lim _{n} z_{n}=x$ imply $\lim _{n} y_{n}=x[11]$.

Lemma 2.3 ([10]) Let $(X, d)$ be a cone metric space with regular cone $\mathrm{P}$ such that $d(x, y) \in \operatorname{int} P$, for $x, y \in X$ with $x \neq y$. Let $\phi: \operatorname{int} P \cup\{0\} \longrightarrow$ $\operatorname{int} P \cup\{0\}$ be a function with the following properties:

(i) $\phi(t)=0$ if and only if $t=0$,

(ii) $\phi(t) \ll t$, for $t \in \operatorname{int} P$ and

(iii) either $\phi(t) \leq d(x, y)$ or $d(x, y) \leq \phi(t)$, for $t \in \operatorname{int} P \cup\{0\}$ and $x, y \in X$.

Let $\left\{x_{n}\right\}$ be a sequence in $X$ for which $\left\{d\left(x_{n}, x_{n+1}\right)\right\}$ is monotonic decreasing. Then $\left\{d\left(x_{n}, x_{n+1}\right)\right\}$ is convergent to either $r=0$ or $r \in$ int $P$.

3. Main Results

Lemma 3.1. Let $(X, d)$ be a cone metric space. Let $\phi: \operatorname{int} P \cup\{0\} \longrightarrow$ $\operatorname{int} P \cup\{0\}$ be a function such that

(i) $\phi(t)=0$ if and only if $t=0$ and

(ii) $\phi(t) \ll t$, for $t \in \operatorname{int} P$. 
Then a sequence $\left\{x_{n}\right\}$ in $X$ is a Cauchy sequence if and only if for every $c \in E$ with $0 \ll c$ there exists $n_{0} \in \mathbf{N}$ such that $d\left(x_{n}, x_{m}\right) \ll \phi(c)$, for all $n, m>n_{0}$. Proof. Let $\left\{x_{n}\right\}$ be a sequence in $X$.

Suppose that $\left\{x_{n}\right\}$ is a Cauchy sequence. Then for every $c \in E$ with $0 \ll c$ there exists $n_{0} \in \mathbf{N}$ such that $d\left(x_{n}, x_{m}\right) \ll c$, for all $n, m>n_{0}$. Let $c \in E$ with $0 \ll c$ be arbitrary. By condition (i) of the lemma $\phi(c) \in \operatorname{int} P$; that is, $0 \ll \phi(c)$. Therefore, there exists $n_{0} \in \mathbf{N}$ such that $d\left(x_{n}, x_{m}\right) \ll \phi(c)$, for all $n, m>n_{0}$.

Conversely suppose that for every $c \in E$ with $0 \ll c$ there exists $n_{0} \in \mathbf{N}$ such that

$d\left(x_{n}, x_{m}\right) \ll \phi(c)$, for all $n, m>n_{0}$.

Since $c \in \operatorname{int} P$, by condition (ii) of the lemma, we have $\phi(c) \ll c$.

Combining the above two inequalities by using the property (ii) of lemma 2.2, we obtain

$d\left(x_{n}, x_{m}\right) \ll c$, for all $n, m>n_{0}$.

Therefore, for every $c \in E$ with $0 \ll c$ there exists $n_{0} \in \mathbf{N}$ such that $d\left(x_{n}, x_{m}\right) \ll c$, for all $n, m>n_{0}$. Hence $\left\{x_{n}\right\}$ is a Cauchy sequence.

Theorem 3.1 Let $(X, \preceq)$ be a partially ordered set and suppose that there exists a cone metric $d$ in $X$ for which the cone metric space $(X, d)$ is complete with regular cone $P$ such that $d(x, y) \in \operatorname{int} P$, for $x, y \in X$ with $x \neq y$. Let $f: X \longrightarrow X$ be a continuous and nondecreasing mapping with respect to $\preceq$ satisfying

$\psi(d(f x, f y)) \leq \psi(M(x, y))-\phi(d(x, y))$, for all $x, y \in X$ with $y \preceq x$,

where

$M(x, y)=p d(x, y)+q[d(x, f x)+d(y, f y)]+r[d(x, f y)+d(y, f x)]$, with $p, q, r \geq 0, p+2 q+2 r \leq 1$, and $\psi: P \longrightarrow P$ and $\phi: \operatorname{int} P \cup\{0\} \longrightarrow$ $\operatorname{int} P \cup\{0\}$ are continuous functions with the following properties:

(i) $\psi$ is strongly monotonic increasing,

(ii) $\psi(t)=0=\phi(t)$ if and only if $t=0$,

(iii) $\phi(t) \ll t$, for $t \in \operatorname{int} P$ and

(iv) either $\phi(t) \leq d(x, y)$ or $d(x, y) \ll \phi(t)$, for $t \in \operatorname{int} P \cup\{0\}$ and $x, y \in X$.

If there exists $x_{0} \in X$ such that $x_{0} \preceq f x_{0}$, then $f$ has a fixed point in $X$.

Proof. If $f x_{0}=x_{0}$, then the proof is completed. Suppose that $f x_{0} \neq x_{0}$. Since $x_{0} \preceq f x_{0}$ and $f$ is nondecreasing w.r.t. $\preceq$, we construct the sequence $\left\{x_{n}\right\}$ such that $x_{n}=f x_{n-1}=f^{n} x_{0}$ and $x_{0} \preceq f x_{0} \preceq f^{2} x_{0} \preceq \ldots \preceq f^{n} x_{0} \preceq$ $f^{n+1} x_{0} \preceq \ldots$; that is, $x_{0} \preceq x_{1} \preceq x_{2} \preceq \ldots \preceq x_{n} \preceq x_{n+1} \preceq \ldots$. 
Clearly, $x_{n} \preceq x_{n+1}$, for each $n \geq 1$. Putting $x=x_{n+1}$ and $y=x_{n}$ in (3.1), we have

$$
\begin{aligned}
\psi\left(d\left(x_{n+2}, x_{n+1}\right)\right) & =\psi\left(d\left(f x_{n+1}, f x_{n}\right)\right) \\
& \leq \psi\left(M\left(x_{n+1}, x_{n}\right)\right)-\phi\left(d\left(x_{n+1}, x_{n}\right)\right) \\
& =\psi\left(p d\left(x_{n+1}, x_{n}\right)+q\left[d\left(x_{n+1}, x_{n+2}\right)+d\left(x_{n}, x_{n+1}\right)\right]\right. \\
& \left.+r\left[d\left(x_{n+1}, x_{n+1}\right)+d\left(x_{n}, x_{n+2}\right)\right]\right)-\phi\left(d\left(x_{n+1}, x_{n}\right)\right) .
\end{aligned}
$$

Since $d\left(x_{n}, x_{n+2}\right) \leq d\left(x_{n}, x_{n+1}\right)+d\left(x_{n+1}, x_{n+2}\right)$, and $\psi$ is strongly monotonic increasing,

it follows that

$$
\begin{gathered}
\psi\left(d\left(x_{n+2}, x_{n+1}\right)\right) \leq \psi\left(p d\left(x_{n+1}, x_{n}\right)+q\left[d\left(x_{n+1}, x_{n+2}\right)+d\left(x_{n}, x_{n+1}\right)\right]\right. \\
\left.+r\left[d\left(x_{n}, x_{n+1}\right)+d\left(x_{n+1}, x_{n+2}\right)\right]\right)-\phi\left(d\left(x_{n+1}, x_{n}\right)\right) .
\end{gathered}
$$

Using a property of $\phi$, we have

$$
\begin{gathered}
\psi\left(d\left(x_{n+2}, x_{n+1}\right)\right) \leq \psi\left(p d\left(x_{n+1}, x_{n}\right)+q\left[d\left(x_{n+1}, x_{n+2}\right)+d\left(x_{n}, x_{n+1}\right)\right]\right. \\
\left.+r\left[d\left(x_{n}, x_{n+1}\right)+d\left(x_{n+1}, x_{n+2}\right)\right]\right) .
\end{gathered}
$$

Using the strongly monotone property of $\psi$, we have

$$
\begin{gathered}
d\left(x_{n+2}, x_{n+1}\right) \leq p d\left(x_{n+1}, x_{n}\right)+q\left[d\left(x_{n+1}, x_{n+2}\right)+d\left(x_{n}, x_{n+1}\right)\right] \\
+r\left[d\left(x_{n}, x_{n+1}\right)+d\left(x_{n+1}, x_{n+2}\right)\right],
\end{gathered}
$$

that is,

$$
(1-q-r) d\left(x_{n+2}, x_{n+1}\right) \leq(p+q+r) d\left(x_{n+1}, x_{n}\right)
$$

that is,

$$
d\left(x_{n+2}, x_{n+1}\right) \leq \frac{(p+q+r)}{(1-q-r)} d\left(x_{n+1}, x_{n}\right),
$$

which implies that

$$
d\left(x_{n+2}, x_{n+1}\right) \leq d\left(x_{n+1}, x_{n}\right),\left(\text { since } \frac{(p+q+r)}{(1-q-r)} \leq 1\right)
$$

Therefore, $\left\{d\left(x_{n+1}, x_{n}\right)\right\}$ is a monotone decreasing sequence. Hence by lemma 2.3 , there exists $u \in P$ with either $u=0$ or $u \in$ int $P$ such that

$$
d\left(x_{n+1}, x_{n}\right) \longrightarrow u \text { as } n \longrightarrow \infty \text {. }
$$

Taking $n \longrightarrow \infty$ in (3.2), using (3.3) and the continuities of $\psi$ and $\phi$, we have $\psi(u) \leq \psi((p+2 q+2 r) u)-\phi(u)$,

which implies that

$\psi(u) \leq \psi(u)-\phi(u)$, (since $p+2 q+2 r \leq 1$ and $\psi$ is strongly monotonic increasing),

which is a contradiction unless $u=0$. Hence,

$$
d\left(x_{n+1}, x_{n}\right) \longrightarrow 0 \text { as } n \longrightarrow \infty \text {. }
$$

Next we show that $\left\{x_{n}\right\}$ is a Cauchy sequence. If $\left\{x_{n}\right\}$ is not a Cauchy sequence, then by lemma 3.1, there exists a $c \in E$ with $0 \ll c$, such that $\forall$ $n_{0} \in \mathbb{N}, \exists n, m \in \mathbb{N}$ with $n>m \geq n_{0}$ such that $d\left(x_{n}, x_{m}\right)<\nless \phi(c)$. Hence by a property of $\phi$ in (iv) of the theorem, $\phi(c) \leq d\left(x_{n}, x_{m}\right)$. Therefore, there exist sequences $\{m(k)\}$ and $\{n(k)\}$ in $\mathbb{N}$ such that for all positive integers $k$, $n(k)>m(k)>k$ and $d\left(x_{n(k)}, x_{m(k)}\right) \geq \phi(c)$.

Assuming that $n(k)$ is the smallest such positive integer, we get $d\left(x_{n(k)}, x_{m(k)}\right) \geq \phi(c)$ 
and

Now,

$$
d\left(x_{n(k)-1}, x_{m(k)}\right) \ll \phi(c) .
$$

$\phi(c) \leq d\left(x_{n(k)}, x_{m(k)}\right) \leq d\left(x_{n(k)}, x_{n(k)-1}\right)+d\left(x_{n(k)-1}, x_{m(k)}\right)$,

that is,

$\phi(c) \leq d\left(x_{n(k)}, x_{m(k)}\right) \leq d\left(x_{n(k)}, x_{n(k)-1}\right)+\phi(c)$.

Letting $k \longrightarrow \infty$ in the above inequality, using (3.4) and the property (v) of

Lemma 2.2, we have

$$
\lim _{k \rightarrow \infty} d\left(x_{n(k)}, x_{m(k)}\right)=\phi(c) .
$$

Again, and

$$
d\left(x_{n(k)}, x_{m(k)}\right) \leq d\left(x_{n(k)}, x_{n(k)+1}\right)+d\left(x_{n(k)+1}, x_{m(k)+1}\right)+d\left(x_{m(k)+1}, x_{m(k)}\right)
$$

$$
d\left(x_{n(k)+1}, x_{m(k)+1}\right) \leq d\left(x_{n(k)+1}, x_{n(k)}\right)+d\left(x_{n(k)}, x_{m(k)}\right)+d\left(x_{m(k)}, x_{m(k)+1}\right) .
$$

Letting $k \longrightarrow \infty$ in above inequalities, using (3.4) and (3.5), we have

$$
\lim _{k \rightarrow \infty} d\left(x_{n(k)+1}, x_{m(k)+1}\right)=\phi(c) .
$$

Again,

and

$$
d\left(x_{n(k)}, x_{m(k)+1}\right) \leq d\left(x_{n(k)}, x_{m(k)}\right)+d\left(x_{m(k)}, x_{m(k)+1}\right)
$$

$d\left(x_{n(k)}, x_{m(k)}\right) \leq d\left(x_{n(k)}, x_{m(k)+1}\right)+d\left(x_{m(k)+1}, x_{m(k)}\right)$

Further,

and

$$
d\left(x_{n(k)+1}, x_{m(k)}\right) \leq d\left(x_{n(k)+1}, x_{n(k)}\right)+d\left(x_{n(k)}, x_{m(k)}\right)
$$

$d\left(x_{n(k)}, x_{m(k)}\right) \leq d\left(x_{n(k)}, x_{n(k)+1}\right)+d\left(x_{n(k)+1}, x_{m(k)}\right)$.

Letting $k \longrightarrow \infty$ in the above four inequalities, using (3.4) and (3.5), we have

$\lim _{k \rightarrow \infty} d\left(x_{n(k)}, x_{m(k)+1}\right)=\phi(c)$,
$\lim _{k \rightarrow \infty} d\left(x_{n(k)+1}, x_{m(k)}\right)=\phi(c)$.

Using (3.4), (3.5), (3.7) and (3.8), we have

$$
\begin{aligned}
\lim _{k \rightarrow \infty} M\left(x_{n(k)}, x_{m(k)}\right) & =\lim _{k \rightarrow \infty}\left[p d\left(x_{n(k)}, x_{m(k)}\right)+q\left(d\left(x_{n(k)}, x_{n(k)+1}\right)+\right.\right. \\
\left.d\left(x_{m(k)}, x_{m(k)+1}\right)\right) & \left.+r\left(d\left(x_{n(k)}, x_{m(k)+1}\right)+d\left(x_{m(k)}, x_{n(k)+1}\right)\right)\right] \\
& =(p+2 r) \phi(c) .
\end{aligned}
$$

Clearly, $x_{m(k)} \preceq x_{n(k)}$. Putting $x=x_{n(k)}, y=x_{m(k)}$ in (3.1), we have $\psi\left(d\left(x_{n(k)+1}, x_{m(k)+1}\right)\right)=\psi\left(d\left(f x_{n(k)}, f x_{m(k)}\right)\right)$

$$
\leq \psi\left(M\left(x_{n(k)}, x_{m(k)}\right)\right)-\phi\left(d\left(x_{n(k)}, x_{m(k)}\right)\right) .
$$

Letting $k \rightarrow \infty$ in the above inequality, using (3.5), (3.6), (3.9) and the continuities of $\psi$ and $\phi$, we have

$$
\psi(\phi(c)) \leq \psi((p+2 r) \phi(c))-\phi(\phi(c)),
$$

that is,

$$
\psi(\phi(c)) \leq \psi(\phi(c))-\phi(\phi(c)),(\text { since } p+2 r \leq 1 \text { and } \psi \text { is strongly monotonic }
$$
increasing), 
which is a contradiction by virtue of a property of $\phi$. Hence $\left\{x_{n}\right\}$ is a Cauchy sequence. From the completeness of $\mathrm{X}$, there exists $z \in X$ such that

$$
x_{n} \longrightarrow z \text { as } n \longrightarrow \infty \text {. }
$$

Since $f$ is continuous and $x_{n} \longrightarrow z$ as $n \longrightarrow \infty$,

$$
\lim _{n \rightarrow \infty} f x_{n}=f z \text {, that is, } \lim _{n \rightarrow \infty} x_{n+1}=f z \text {, that is, } z=f z \text {. }
$$

Hence $z$ is a fixed point of $f$ and the proof is completed.

Theorem 3.2 Let $(X, \preceq)$ be a partially ordered set and suppose that there exists a cone metric $d$ in $X$ for which the cone metric space $(X, d)$ is complete with regular cone $P$ such that $d(x, y) \in \operatorname{int} P$, for $x, y \in X$ with $x \neq y$. Assume that if $\left\{x_{n}\right\}$ is a nondecreasing sequence in $X$ such that $x_{n} \longrightarrow x$ then $x_{n} \preceq x$, for all $n \in \mathbf{N}$. Let $f: X \longrightarrow X$ be a nondecreasing mapping with respect to $\preceq$. Suppose that (3.1) holds, where $M(x, y)$ and the conditions upon $(\phi, \psi)$ are the same as in Theorem 3.1. If there exists $x_{0} \in X$ such that $x_{0} \preceq f x_{0}$, then $f$ has a fixed point in $X$.

Proof. We take the same sequence $\left\{x_{n}\right\}$ as in the proof of Theorem 3.1. Then we have $x_{0} \preceq x_{1} \preceq x_{2} \preceq \ldots \preceq x_{n} \preceq x_{n+1} \preceq \ldots$; that is, $\left\{x_{n}\right\}$ is a nondecreasing sequence. Also, this sequence converges to $z$. Then $x_{n} \preceq z$, for all $n \in \mathbf{N}$. Therefore, we can use the condition (3.1) and so we have

$$
\begin{aligned}
\psi\left(d\left(f z, x_{n+1}\right)\right)= & \psi\left(d\left(f z, f x_{n}\right)\right) \\
\leq & \psi\left(M\left(z, x_{n}\right)\right)-\phi\left(d\left(z, x_{n}\right)\right) \\
= & \psi\left(p d\left(z, x_{n}\right)+q\left[d(z, f z)+d\left(x_{n}, x_{n+1}\right)\right]\right. \\
& \left.+r\left[d\left(z, x_{n+1}\right)+d\left(x_{n}, f z\right)\right]\right)-\phi\left(d\left(z, x_{n}\right)\right) .
\end{aligned}
$$

Taking $n \longrightarrow \infty$ in the above inequality and using properties of $\psi$ and $\phi$, we have

$$
\psi(d(f z, z)) \leq \psi((q+r) d(z, f z)) .
$$

Since $p+2 q+2 r \leq 1$ implies $q+r \leq \frac{1}{2}$, and $\psi$ is strongly monotonic increasing, it follows that

$$
d(f z, z) \leq \frac{1}{2} d(z, f z)
$$

which is a contradiction unless $f z=z$. Hence $z$ is a fixed point of $f$ and the proof is completed.

Remark 3.1 From the contractive condition (3.1), we have (by the property of $\psi$ and $\phi)$ where

$$
d(f x, f y) \leq M(x, y), \text { for all } x, y \in X \text { with } y \preceq x,
$$

$$
M(x, y)=p d(x, y)+q[d(x, f x)+d(y, f y)]+r[d(x, f y)+d(y, f x)]
$$

with $p, q, r \geq 0$ and $p+2 q+2 r \leq 1$.

So, if $p+2 q+2 r<1$, Theorem 3.1 is directly reducible to the statement in [24]. On the other hand, if $E=R, P=R_{+}$, Theorem 3.1 is reducible to the result in [1]. The last statement follows by a result of [18].

Theorem 3.3 Let $(X, \preceq)$ be a partially ordered set and suppose that there exists a cone metric $d$ in $X$ for which the cone metric space $(X, d)$ is complete 
with regular cone $P$ such that $d(x, y) \in \operatorname{int} P$, for $x, y \in X$ with $x \neq y$. Let $f, g: X \longrightarrow X$ be two weakly increasing mappings with respect to $\preceq$ satisfying

$\psi(d(f x, g y)) \leq \psi(M(x, y))-\phi(d(x, y))$, for all comparative $x, y \in X$,

where

$M(x, y)=p d(x, y)+q[d(x, f x)+d(y, g y)]+r[d(x, g y)+d(y, f x)]$, with $p, q, r \geq 0, p+2 q+2 r \leq 1$, and the conditions upon $(\phi, \psi)$ are the same as in Theorem 3.1. If $f$ or $g$ is continuous, then $f$ and $g$ have a common fixed point in $\mathrm{X}$.

Proof. Let $x_{0} \in X$ be arbitrary. We construct the sequence $\left\{x_{n}\right\}$ such that $x_{2 n+1}=f x_{2 n}$ and $x_{2 n+2}=g x_{2 n+1}$, for all $n \geq 0$. Since $f$ and $g$ are weakly increasing, we have $x_{1}=f x_{0} \preceq g f x_{0}=g x_{1}=x_{2}$, and $x_{2}=g x_{1} \preceq f g x_{1}=$ $f x_{2}=x_{3}$. Continuing this process we have $x_{1} \preceq x_{2} \preceq x_{3} \preceq \ldots \preceq x_{n} \preceq x_{n+1} \preceq$ .... Therefore, sequence $\left\{x_{n}\right\}$ is nondecreasing. Since $x_{2 n-1}$ and $x_{2 n}$ are comparative, for all $n \geq 1$ we have from $(3.11)$

$$
\begin{aligned}
\psi\left(d\left(f x_{2 n}, g x_{2 n-1}\right)\right) & \leq \psi\left(M\left(x_{2 n}, x_{2 n-1}\right)\right)-\phi\left(d\left(x_{2 n}, x_{2 n-1}\right)\right) \\
= & \psi\left(p d\left(x_{2 n}, x_{2 n-1}\right)+q\left[d\left(x_{2 n}, f x_{2 n}\right)+d\left(x_{2 n-1}, g x_{2 n-1}\right)\right]\right. \\
+ & {\left.\left[d\left(x_{2 n}, g x_{2 n-1}\right)+d\left(x_{2 n-1}, f x_{2 n}\right)\right]\right)-\phi\left(d\left(x_{2 n}, x_{2 n-1}\right)\right) }
\end{aligned}
$$

that is,

$$
\begin{array}{r}
\psi\left(d\left(x_{2 n+1}, x_{2 n}\right)\right) \leq \psi\left(p d\left(x_{2 n}, x_{2 n-1}\right)+q\left[d\left(x_{2 n}, x_{2 n+1}\right)+d\left(x_{2 n-1}, x_{2 n}\right)\right]\right. \\
\left.+r\left[d\left(x_{2 n}, x_{2 n}\right)+d\left(x_{2 n-1}, x_{2 n+1}\right)\right]\right)-\phi\left(d\left(x_{2 n}, x_{2 n-1}\right)\right) .
\end{array}
$$

Since $d\left(x_{2 n-1}, x_{2 n+1}\right) \leq d\left(x_{2 n-1}, x_{2 n}\right)+d\left(x_{2 n}, x_{2 n+1}\right)$, and $\psi$ is strongly monotonic increasing, it follows that

$$
\begin{array}{r}
\psi\left(d\left(x_{2 n+1}, x_{2 n}\right)\right) \leq \psi\left(p d\left(x_{2 n}, x_{2 n-1}\right)+q\left[d\left(x_{2 n}, x_{2 n+1}\right)+d\left(x_{2 n-1}, x_{2 n}\right)\right]\right. \\
\left.+r\left[d\left(x_{2 n-1}, x_{2 n}\right)+d\left(x_{2 n}, x_{2 n+1}\right)\right]\right)-\phi\left(d\left(x_{2 n}, x_{2 n-1}\right)\right) .
\end{array}
$$

Using a property of $\phi$, we have

$$
\begin{gathered}
\psi\left(d\left(x_{2 n+1}, x_{2 n}\right)\right) \leq \psi\left(p d\left(x_{2 n}, x_{2 n-1}\right)+q\left[d\left(x_{2 n}, x_{2 n+1}\right)+d\left(x_{2 n-1}, x_{2 n}\right)\right]\right. \\
\left.+r\left[d\left(x_{2 n-1}, x_{2 n}\right)+d\left(x_{2 n}, x_{2 n+1}\right)\right]\right) .
\end{gathered}
$$

Using the strongly monotone property of $\psi$, we have

that is,

$$
\begin{aligned}
d\left(x_{2 n+1}, x_{2 n}\right) \leq & p d\left(x_{2 n}, x_{2 n-1}\right)+q\left[d\left(x_{2 n}, x_{2 n+1}\right)+d\left(x_{2 n-1}, x_{2 n}\right)\right] \\
& +r\left[d\left(x_{2 n-1}, x_{2 n}\right)+d\left(x_{2 n}, x_{2 n+1}\right)\right],
\end{aligned}
$$

that is,

$$
(1-q-r) d\left(x_{2 n+1}, x_{2 n}\right) \leq(p+q+r) d\left(x_{2 n}, x_{2 n-1}\right),
$$

$$
d\left(x_{2 n+1}, x_{2 n}\right) \leq \frac{(p+q+r)}{(1-q-r)} d\left(x_{2 n}, x_{2 n-1}\right),
$$

which implies that

$$
d\left(x_{2 n+1}, x_{2 n}\right) \leq d\left(x_{2 n}, x_{2 n-1}\right),\left(\text { since } \frac{(p+q+r)}{(1-q-r)} \leq 1\right) .
$$

Similarly, we can show that

$$
d\left(x_{2 n+2}, x_{2 n+1}\right) \leq d\left(x_{2 n+1}, x_{2 n}\right) .
$$


In view of above facts, $\left\{d\left(x_{n+1}, x_{n}\right)\right\}$ is a monotone decreasing sequence. Hence by lemma 2.3, there exists $u \in P$ with either $u=0$ or $u \in \operatorname{int} P$ such that

$$
d\left(x_{n+1}, x_{n}\right) \longrightarrow u \text { as } n \longrightarrow \infty .
$$

Taking $n \longrightarrow \infty$ in (3.12), using (3.13) and the continuities of $\psi$ and $\phi$, we have

$$
\psi(u) \leq \psi((p+2 q+2 r) u)-\phi(u),
$$

which implies that

$\psi(u) \leq \psi(u)-\phi(u)$, (since $p+2 q+2 r \leq 1$ and $\psi$ is strongly monotonic increasing),

which is a contradiction unless $u=0$. Hence

$$
d\left(x_{n}, x_{n+1}\right) \longrightarrow 0 \text { as } n \longrightarrow \infty \text {. }
$$

Now we show that $\left\{x_{n}\right\}$ is a Cauchy sequence. By virtue of (3.14), it is sufficient to prove that $\left\{x_{2 n}\right\}$ is a Cauchy sequence. If $\left\{x_{2 n}\right\}$ is not a Cauchy sequence, then by lemma 3.1 there exists a $c \in E$ with $0 \ll c$ such that $\forall$ $n_{0} \in \mathbb{N}, \exists n, m \in \mathbb{N}$ with $2 n>2 m \geq n_{0}$ such that $d\left(x_{2 m}, x_{2 n}\right)<\nless \phi(c)$. Hence by a property of $\phi$ in (iv) of the theorem, $\phi(c) \leq d\left(x_{2 m}, x_{2 n}\right)$. Therefore, there exist sequences $\{2 m(k)\}$ and $\{2 n(k)\}$ in $\mathbb{N}$ such that for all positive integers $k$,

$$
2 n(k)>2 m(k)>k \text { and } d\left(x_{2 m(k)}, x_{2 n(k)}\right) \geq \phi(c) .
$$

Assuming that $2 n(k)$ is the smallest such positive integer, we get

and

$$
d\left(x_{2 m(k)}, x_{2 n(k)}\right) \geq \phi(c)
$$

Now,

$$
d\left(x_{2 m(k)}, x_{2 n(k)-2}\right) \ll \phi(c) .
$$

$$
\phi(c) \leq d\left(x_{2 m(k)}, x_{2 n(k)}\right) \leq d\left(x_{2 m(k)}, x_{2 n(k)-2}\right)+d\left(x_{2 n(k)-2}, x_{2 n(k)-1}\right)+
$$
$d\left(x_{2 n(k)-1}, x_{2 n(k)}\right)$,

that is,

$$
\phi(c) \leq d\left(x_{2 m(k)}, x_{2 n(k)}\right) \leq \phi(c)+d\left(x_{2 n(k)-2}, x_{2 n(k)-1}\right)+d\left(x_{2 n(k)-1}, x_{2 n(k)}\right) .
$$

Letting $k \longrightarrow \infty$ in the above inequality, using (3.14) and the property (v) of lemma 2.2 , we have

$$
\lim _{k \rightarrow \infty} d\left(x_{2 m(k)}, x_{2 n(k)}\right)=\phi(c) .
$$

Again,

$$
\begin{aligned}
& \text { and } \\
& \quad d\left(x_{2 m(k)+1}, x_{2 n(k)+1}\right) \leq d\left(x_{2 m(k)+1}, x_{2 m(k)}\right)+d\left(x_{2 m(k)}, x_{2 n(k)}\right)+ \\
& \quad+d\left(x_{2 n(k)}, x_{2 n(k)+1}\right) .
\end{aligned}
$$$$
d\left(x_{2 m(k)}, x_{2 n(k)}\right) \leq d\left(x_{2 m(k)}, x_{2 m(k)+1}\right)+d\left(x_{2 m(k)+1}, x_{2 n(k)+1}\right)+
$$$$
+d\left(x_{2 n(k)+1}, x_{2 n(k)}\right)
$$

Letting $k \longrightarrow \infty$ in the above inequalities and using (3.14) and (3.15), we have

$$
\lim _{k \rightarrow \infty} d\left(x_{2 m(k)+1}, x_{2 n(k)+1}\right)=\phi(c) .
$$

Again, 
$\quad d\left(x_{2 m(k)+1}, x_{2 n(k)+2}\right) \leq d\left(x_{2 m(k)+1}, x_{2 n(k)+1}\right)+d\left(x_{2 n(k)+1}, x_{2 n(k)+2}\right)$
and
\[ d\left(x_{2 m(k)+1}, x_{2 n(k)+1}\right) \leq d\left(x_{2 m(k)+1}, x_{2 n(k)+2}\right)+d\left(x_{2 n(k)+2}, x_{2 n(k)+1}\right) . \]

Again,

$$
\begin{aligned}
& d\left(x_{2 m(k)}, x_{2 n(k)+2}\right) \leq d\left(x_{2 m(k)}, x_{2 n(k)}\right)+d\left(x_{2 n(k)}, x_{2 n(k)+1}\right)+ \\
& +d\left(x_{2 n(k)+1}, x_{2 n(k)+2}\right)
\end{aligned}
$$

and

$$
d\left(x_{2 m(k)}, x_{2 n(k)}\right) \leq d\left(x_{2 m(k)}, x_{2 n(k)+2}\right)+d\left(x_{2 n(k)+2}, x_{2 n(k)+1}\right)+
$$$$
+d\left(x_{2 n(k)+1}, x_{2 n(k)}\right) \text {. }
$$

Further, and

$$
d\left(x_{2 m(k)}, x_{2 n(k)+1}\right) \leq d\left(x_{2 m(k)}, x_{2 n(k)}\right)+d\left(x_{2 n(k)}, x_{2 n(k)+1}\right)
$$

$d\left(x_{2 m(k)}, x_{2 n(k)}\right) \leq d\left(x_{2 m(k)}, x_{2 n(k)+1}\right)+d\left(x_{2 n(k)+1}, x_{2 n(k)}\right)$.

Letting $k \longrightarrow \infty$ in the above six inequalities and using (3.14), (3.15) and (3.16), we have respectively

$$
\begin{aligned}
& \lim _{k \rightarrow \infty} d\left(x_{2 m(k)+1}, x_{2 n(k)+2}\right)=\phi(c), \\
& \quad \lim _{k \rightarrow \infty} d\left(x_{2 m(k)}, x_{2 n(k)+2}\right)=\phi(c) \\
& \text { and } \lim _{k \rightarrow \infty} d\left(x_{2 m(k)}, x_{2 n(k)+1}\right)=\phi(c) .
\end{aligned}
$$

Using (3.14), (3.16), (3.18) and (3.19), we have

$\lim _{k \rightarrow \infty} M\left(x_{2 m(k)}, x_{2 n(k)+1}\right)=\lim _{k \rightarrow \infty}\left[p d\left(x_{2 m(k)}, x_{2 n(k)+1}\right)+q\left(d\left(x_{2 m(k)}, x_{2 m(k)+1}\right)+\right.\right.$ $\left.d\left(x_{2 n(k)+1}, x_{2 n(k)+2}\right)\right)$

$$
\begin{aligned}
& \left.+r\left(d\left(x_{2 m(k)}, x_{2 n(k)+2}\right)+d\left(x_{2 n(k)+1}, x_{2 m(k)+1}\right)\right)\right] \\
& =(p+2 r) \phi(c) .
\end{aligned}
$$

Clearly, $x_{2 m(k)}$ and $x_{2 n(k)+1}$ are comparative. So, for $x=x_{2 m(k)}, y=$ $x_{2 n(k)+1}$, we have from $(3.11)$,

$$
\begin{aligned}
\psi\left(d\left(x_{2 m(k)+1}, x_{2 n(k)+2}\right)\right) & =\psi\left(d\left(f x_{2 m(k)}, g x_{2 n(k)+1}\right)\right) \\
\leq & \psi\left(M\left(x_{2 m(k)}, x_{2 n(k)+1}\right)\right)-\phi\left(d\left(x_{2 m(k)}, x_{2 n(k)+1}\right)\right) .
\end{aligned}
$$

Letting $k \rightarrow \infty$ in the above inequality, using (3.17), (3.19), (3.20) and the continuities of $\psi$ and $\phi$, we have

$$
\psi(\phi(c)) \leq \psi((p+2 r) \phi(c))-\phi(\phi(c)),
$$

that is,

$\psi(\phi(c)) \leq \psi(\phi(c))-\phi(\phi(c)),($ since $p+2 r \leq 1$ and $\psi$ is strongly monotonic increasing),

which is a contradiction by virtue of a property of $\phi$. Therefore, $\left\{x_{2 n}\right\}$ is a Cauchy sequence. Hence in view of $(3.14),\left\{x_{n}\right\}$ is a Cauchy sequence. From the completeness of $\mathrm{X}$, there exists $z \in X$ such that

$$
x_{n} \longrightarrow z \text { as } n \longrightarrow \infty \text {. }
$$

Suppose that $f$ is continuous.

In view of $(3.21),\left\{x_{2 n+2}\right\}=\left\{g x_{2 n+1}\right\} \longrightarrow z$ and $\left\{x_{2 n+3}\right\}=\left\{f x_{2 n+2}\right\} \longrightarrow z$, 
as $n \longrightarrow \infty$.

Since $f$ is continuous and $\left\{x_{2 n+2}\right\}=\left\{g x_{2 n+1}\right\} \longrightarrow z$ as $n \longrightarrow \infty$, $\lim _{n \rightarrow \infty} f g x_{2 n+1}=f z$, that is, $\lim _{n \rightarrow \infty} f x_{2 n+2}=f z$, that is, $z=f z$.

Hence $z$ is a fixed point of $f$.

We must show that $z$ is also a fixed point of $g$. Since $z \preceq z$, we can use the inequality (3.11) for $x=z$ and $y=z$; then we have

$$
\begin{aligned}
\psi(d(f z, g z)) \leq \psi & (M(z, z))-\phi(d(z, z)) \\
=\psi & (p d(z, z)+q[d(z, f z)+d(z, g z)] \\
& +r[d(z, g z)+d(z, f z)])-\phi(d(z, z)),
\end{aligned}
$$

which implies that

$$
\psi(d(z, g z)) \leq \psi((q+r) d(z, g z)) .
$$

Since $p+2 q+2 r \leq 1$ implies $q+r \leq \frac{1}{2}$, and $\psi$ is strongly monotonic increasing, it follows that

$$
d(z, g z) \leq \frac{1}{2} d(z, g z)
$$

which is a contradiction unless $z=g z$. Hence $z$ is a common fixed point of $f$ and $g$.

Similarly, if $g$ is continuous, then $z$ is a common fixed point of $f$ and $g$.

Therefore, $f$ and $g$ have a common fixed point.

The following theorem is a variant of Theorem 3.3.

Theorem 3.4 Let $(X, \preceq)$ be a partially ordered set and suppose that there exists a cone metric $d$ in $X$ for which the cone metric space $(X, d)$ is complete with regular cone $P$ such that $d(x, y) \in \operatorname{int} P$, for $x, y \in X$ with $x \neq y$. Assume that if $\left\{x_{n}\right\}$ is a nondecreasing sequence in $X$ such that $x_{n} \longrightarrow x$ then $x_{n} \preceq x$, for all $n \in \mathbf{N}$. Let $f, g: X \longrightarrow X$ be two weakly increasing mappings with respect to $\preceq$ satisfying (3.11), where $M(x, y)$ and the conditions upon $(\phi, \psi)$ are the same as in Theorem 3.3. Then $f$ and $g$ have a common fixed point in $\mathrm{X}$.

Example 3.1 Let $X=\{\alpha, \beta, \gamma, \delta\}$ with the partial order $\preceq$ for which $\gamma \preceq \delta \preceq \alpha \preceq \beta$. Then $(X, \preceq)$ be a partially ordered set. Let $E=\mathbb{R}^{2}$, with usual norm, be a real Banach space. We define $P=\{(x, y) \in E: x, y \geq 0\}$. The partial ordering $\leq$ with respect to the cone $\mathrm{P}$ be the partial ordering in E. Then $P$ is a regular cone. Let $d: X \times X \longrightarrow E$ be given as follows: $d(\alpha, \beta)=d(\beta, \alpha)=(0.5,0.5), d(\alpha, \gamma)=d(\gamma, \alpha)=(2,3), d(\alpha, \delta)=$ $d(\delta, \alpha)=(2,2.5), d(\beta, \gamma)=d(\gamma, \beta)=(2,3), d(\beta, \delta)=d(\delta, \beta)=$ $(2,2.5), d(\gamma, \delta)=d(\delta, \gamma)=(2,2.6)$ and $d(\alpha, \alpha)=d(\beta, \beta)=d(\gamma, \gamma)=$ $d(\delta, \delta)=(0,0)$.

Then $(X, d)$ is a complete cone metric space with the required properties of Theorems 3.1 and 3.2.

Let $\psi: P \longrightarrow P$ and $\phi: \operatorname{int} P \cup\{0\} \longrightarrow \operatorname{int} P \cup\{0\}$ be defined respectively as follows:

For $t=(x, y) \in P$, 
and

$$
\psi(t)=\left\{\begin{array}{l}
(x, y), \text { if } x \leq 1 \text { and } y \leq 1 \\
\left(x^{2}, y\right), \text { if } x>1 \text { and } y \leq 1 \\
\left(x, y^{2}\right), \text { if } x \leq 1 \text { and } y>1 \\
\left(x^{2}, y^{2}\right), \text { if } x>1 \text { and } y>1
\end{array}\right.
$$

for $s=\left(s_{1}, s_{2}\right) \in \operatorname{int} P \cup\{0\}$ with $v=\min \left\{s_{1}, s_{2}\right\}$,

$$
\phi(s)= \begin{cases}\left(\frac{v^{2}}{2}, \frac{v^{2}}{2}\right), & \text { if } \quad v \leq 1, \\ \left(\frac{1}{2}, \frac{1}{2}\right), & \text { if } \quad v>1 .\end{cases}
$$

Then $\psi$ and $\phi$ have the properties mentioned in Theorems 3.1 and 3.2.

Let $f: X \longrightarrow X$ be defined as follows:

$$
f \alpha=\beta, f \beta=\beta, f \gamma=\alpha \text { and } f \delta=\beta .
$$

Then $f$ has the required properties mentioned in Theorems 3.1 and 3.2.

Let $p=\frac{1}{2}, q=\frac{1}{8}$ and $r=\frac{1}{8}$.

It can be verified that

$$
\psi(d(f x, f y)) \leq \psi(M(x, y))-\phi(d(x, y)) \text {, for all } x, y \in X \text { with } y \preceq x .
$$

The conditions of Theorems 3.1 and 3.2 are satisfied. Here it is seen that $\beta$ is a fixed point of $f$.

Example 3.2 Let $X=[0,1]$ with usual order $\preceq$ be a partially ordered set. Let $E=\mathbb{R}^{2}$, with usual norm, be a real Banach space. We define $P=\{(x, y) \in E: x, y \geq 0\}$. The partial ordering $\leq$ with respect to the cone $\mathrm{P}$ be the partial ordering in $\mathrm{E}$. Then $P$ is a regular cone. Let $d: X \times X \longrightarrow E$ be given as follows:

$$
d(x, y)=(|x-y|,|x-y|), \text { for } x, y \in X .
$$

Then $(X, d)$ is a complete cone metric space with the required properties of Theorem 3.2.

Let $\psi: P \longrightarrow P$ and $\phi: \operatorname{int} P \cup\{0\} \longrightarrow \operatorname{int} P \cup\{0\}$ be defined respectively as follows:

For $t=(x, y) \in P$,

$$
\psi(t)=\left\{\begin{array}{l}
(x, y), \text { if } x \leq 1 \text { and } y \leq 1 \\
\left(x^{2}, y\right), \text { if } x>1 \text { and } y \leq 1 \\
\left(x, y^{2}\right), \text { if } x \leq 1 \text { and } y>1 \\
\left(x^{2}, y^{2}\right), \text { if } x>1 \text { and } y>1
\end{array}\right.
$$

and

for $s=\left(s_{1}, s_{2}\right) \in \operatorname{int} P \cup\{0\}$ with $v=\min \left\{s_{1}, s_{2}\right\}$,

$$
\phi(s)= \begin{cases}\left(\frac{v^{2}}{2}, \frac{v^{2}}{2}\right), & \text { if } v \leq 1, \\ \left(\frac{1}{2}, \frac{1}{2}\right), & \text { if } v>1 .\end{cases}
$$

Then $\psi$ and $\phi$ have the properties mentioned in Theorem 3.2.

Let $f: X \longrightarrow X$ be defined as follows:

$$
f x=\left\{\begin{array}{c}
0, \quad \text { if } \quad 0 \leq x \leq \frac{1}{2}, \\
\frac{1}{16}, \text { if } \quad \frac{1}{2}<x \leq 1 .
\end{array}\right.
$$


Then $f$ has the required properties mentioned in Theorem 3.2.

Let $p=\frac{1}{2}, q=\frac{1}{8}$ and $r=\frac{1}{8}$.

It can be verified that

$\psi(d(f x, f y)) \leq \psi(M(x, y))-\phi(d(x, y))$, for all $x, y \in X$ with $y \preceq x$.

The conditions of Theorem 3.2 are satisfied. Here it is seen that 0 is a fixed point of $f$.

Example 3.3 Let $X=[0,1]$ with usual order $\preceq$ be a partially ordered set. Let $E=\mathbb{R}^{2}$, with usual norm, be a real Banach space. We define $P=\{(x, y) \in E: x, y \geq 0\}$. The partial ordering $\leq$ with respect to the cone $\mathrm{P}$ be the partial ordering in E. Then $P$ is a regular cone. Let $d: X \times X \longrightarrow E$ be given as follows:

$$
d(x, y)=(|x-y|,|x-y|), \text { for } x, y \in X
$$

Then $(X, d)$ is a complete cone metric space with the required properties of Theorems 3.3 and 3.4 .

Let $\psi: P \longrightarrow P$ and $\phi: \operatorname{int} P \cup\{0\} \longrightarrow \operatorname{int} P \cup\{0\}$ be defined respectively as follows:

For $t=(x, y) \in P$,

$$
\psi(t)=\left\{\begin{array}{l}
(x, y), \text { if } x \leq 1 \text { and } y \leq 1 \\
\left(x^{2}, y\right), \text { if } x>1 \text { and } y \leq 1 \\
\left(x, y^{2}\right), \text { if } x \leq 1 \text { and } y>1 \\
\left(x^{2}, y^{2}\right), \text { if } x>1 \text { and } y>1
\end{array}\right.
$$

and

for $s=\left(s_{1}, s_{2}\right) \in \operatorname{int} P \cup\{0\}$ with $v=\min \left\{s_{1}, s_{2}\right\}$,

$$
\phi(s)= \begin{cases}\left(\frac{v^{2}}{2}, \frac{v^{2}}{2}\right), & \text { if } v \leq 1, \\ \left(\frac{1}{2}, \frac{1}{2}\right), & \text { if } v>1 .\end{cases}
$$

Then $\psi$ and $\phi$ have the properties mentioned in Theorems 3.3 and 3.4.

Let $f, g: X \longrightarrow X$ be defined respectively as follows:

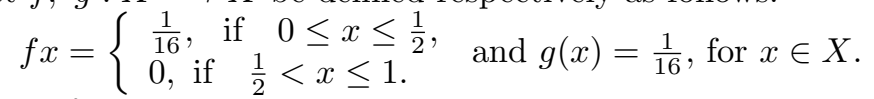

Then $f$ and $g$ have the required properties mentioned in Theorems 3.3 and 3.4 .

Let $p=\frac{1}{2}, q=\frac{1}{8}$ and $r=\frac{1}{8}$.

It can be verified that for all comparative $x, y \in X$ $\psi(d(f x, g y)) \leq \psi(M(x, y))-\phi(d(x, y))$.

The conditions of Theorems 3.3 and 3.4 are satisfied. Here it is seen that $\frac{1}{16}$ is a common fixed point of $f$ and $g$.

Acknowledgement: The authors gratefully acknowledge the suggestions made by the learned referee. The work is partially supported by Council of Scientific and Industrial Research, India(No. 25(0168)/ 09/EMR-II). The first author gratefully acknowledges the support. 


\section{References}

[1] R. P. Agarwal, M. A. El-Gebeily, D. O'Regan, Generalized contractions in partially ordered metric spaces, Applicable Analysis 87 (2008), 109-116.

[2] Ya. I. Alber, S. Guerre-Delabriere, Principles of weakly contractive maps in Hilbert spaces, in :I. Gohberg, Yu. Lyubich(Eds.), New Results in Operator Theory, in : Advances and Appl. 98, Birkhuser, Basel, 1997, $7-22$.

[3] I. Altun, B. Damjanovic, D. Djoric, Fixed point and common fixed point theorems on ordered cone metric spaces, Appl. Math. Lett. 23 (2010), 310-316.

[4] C. E. Chidume, H. Zegeye, S. J. Aneke, Approximation of fixed points of weakly contractive nonself maps in Banach spaces, J. Math. Anal. Appl. 270(1) (2002), 189-199.

[5] B. S. Choudhury, A common unique fixed point result in metric spaces involving generalised altering distances, Math. Commun. 10 (2005), 105110.

[6] B. S. Choudhury, P. N. Dutta, Common fixed points for fuzzy mappings using generalized altering distances, Soochow J. Math. 31(1) (2005), 7181.

[7] B. S. Choudhury, K. Das, A coincidence point result in Menger spaces using a control function, Chaos Solitons and Fractals 42 (2009), 30583063 .

[8] B. S. Choudhury, P. N. Dutta, K. Das, A fixed points result in Menger space using a real function, Acta. Math. Hungar. 122 (2009), 203-216.

[9] B. S. Choudhury, N. Metiya, Fixed points of weak contractions in cone metric spaces, Nonlinear Anal. 72 (2010), 1589-1593.

[10] B. S. Choudhury, N. Metiya, The point of coincidence and common fixed point for a pair of mappings in cone metric spaces, Comput. Math. Appl. 60 (2010), 1686-1695.

[11] K. Deimling, Nonlinear Functional Analysis, Springer-Verlage, 1985.

[12] D. Dorić, Common fixed point for generalized $(\psi, \varphi)$-weak contractions, Appl. Math. Lett. 22 (2009), 1896-1900. 
[13] P. N. Dutta, B. S. Choudhury, A generalisation of contraction principle in metric spaces, Fixed Point Theory Appl. 2008 (2008), Article ID 406368.

[14] R. H. Haghi, Sh. Rezapour, Fixed points of multifunctions on regular cone metric spaces, Expo. Math. 28 (2010), 71-77.

[15] J. Harjani, K. Sadarangani, Fixed point theorems for weakly contractive mappings in partially ordered sets, Nonlinear Anal. 71 (2009), 3403-3410.

[16] L. G. Huang, X. Zhang, Cone metric spaces and fixed point theorems of contractive mappings, J. Math. Anal. Appl. 332 (2007), 1468-1476.

[17] D. Ilić, V. Rakočević, Common fixed point for maps on cone metric space, J. Math. Anal. Appl. 341 (2008), 876-882.

[18] J. Jachymski, Equivalent conditions for generalized contractions on (ordered) metric spaces, Nonlinear Anal. 74 (2011), 768-774.

[19] S. Janković, Z. Kadelburg, S. Radenović, B. E. Rhoades, Assad-KirkType Fixed Point Theorems for a Pair of Nonself Mappings on Cone Metric Spaces, Fixed Point Theory Appl. Volume 2009 (2009), Article ID 761086, 16 pages.

[20] G. Jungck, S. Radenović, S. Radojević, V. Rakočević, Common fixed point theorems for weakly compatible pairs on cone metric spaces, Fixed Point Theory Appl. Volume 2009 (2009), Article ID 643840, 13 pages.

[21] M. S. Khan, M. Swaleh, S. Sessa, Fixed points theorems by altering distances between the points, Bull. Austral. Math. Soc. 30 (1984), 1-9.

[22] S. V. R. Naidu, Some fixed point theorems in metric spaces by altering distances, Czechoslovak Math. Jr. 53(1) (2003), 205-212.

[23] J. J. Nieto, R. Rodrguez-Lpez, Existence and uniqueness of fixed point in partially ordered sets and applications to ordinary differential equations, Acta Math. Sinica 23 (2007), 2205-2212.

[24] J. O. Olaleru, Some generalizations of fixed point theorems in cone metric spaces, Fixed Point Theory Appl. Volume 2009 (2009), Article ID 657914, $10 \mathrm{pp}$.

[25] A. C. M. Ran, M. C. B. Reurings, A fixed point theorem in partially ordered sets and some applications to matrix equations, Proc. Amer. Math. Soc. 132 (2004), 1435-1443. 
[26] B. E. Rhoades, Some theorems on weakly contractive maps, Nonlinear Anal. 47(4) (2001), 2683-2693.

[27] K. P. R. Sastry, G. V. R. Babu, Some fixed point theorems by altering distances between the points, Ind. J. Pure. Appl. Math. 30(6) (1999), 641-647.

[28] M. Turinici, Abstract comparison principles and multivariable GronwallBellman inequalities, J. Math. Anal. Appl. 117 (1986), 100-127.

[29] Q. Zhang, Y. Song, Fixed point theory for generalized $\phi-$ weak contractions, Appl. Math. Lett. 22(1) (2009), 75-78.

Binayak S. Choudhury,

Department of Mathematics,

Bengal Engineering and Science University,

Shibpur, Howrah - 711103, West Bengal, India

Email: binayak12@yahoo.co.in, binayak@becs.ac.in

Binayak S. Choudhury,

Department of Mathematics,

Bengal Institute of Technology,

Kolkata - 700150, West Bengal, India

Email: metiya.nikhilesh@gmail.com 
Binayak S. Choudhury, N. Metiya 